\title{
Holismo só na teoria: a trama de sentimentos do acadêmico de enfermagem sobre sua formação*
}

\author{
HOLISM ONLY IN THEORY: THE STRUGGLE OF NURSING STUDENT'S FEELINGS \\ ABOUT THEIR EDUCATION PROCESS
}

\author{
HOLISMO SÓLO EN LA TEORÍA: LA TRAMA DE SENTIMIENTOS DEL ESTUDIANTE \\ DE ENFERMERÍA SOBRE SU FORMACÍON
}

\section{Elizabeth Esperidião1, Denize Bouttelet Munari²}
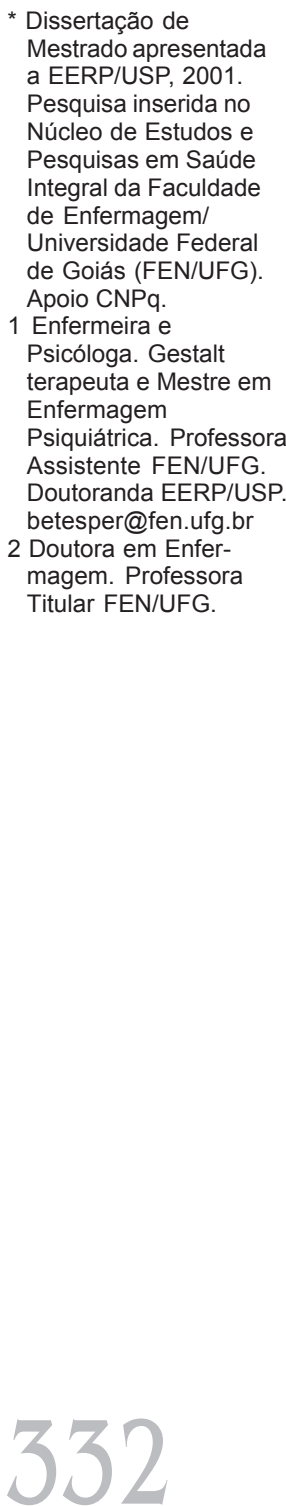

\author{
RESUMO \\ Apesar da busca da \\ integralidade do ser humano, \\ observamos que a formação \\ do enfermeiro enfatiza a \\ dimensão técnica e pouco \\ possibilita o crescimento \\ interno do profissional. \\ Procurando compreender \\ esse processo, objetivamos \\ identificar e analisar a \\ percepção e sentimentos de \\ acadêmicos de Enfermagem \\ relativos à sua formação \\ como pessoa/profissional no \\ âmbito da Enfermagem. Os \\ relatos submetidos à análise \\ de conteúdo apontaram duas \\ categorias: Holismo só na \\ teoria e a Trama dos \\ sentimentos, que revelaram \\ ser esta uma etapa de muitas \\ descobertas e pouco espaço \\ para a pessoa do aluno. Os \\ resultados da pesquisa \\ oferecem elementos \\ importantes a serem \\ repensados pelas Escolas \\ visando a formação do aluno \\ como pessoa integral/ \\ integrada.
}

PALAVRAS-CHAVE

Enfermagem holística. Educação em enfermagem. Saúde mental.

\begin{abstract}
Despite the speech of the human being's integration, we have observed that the nurse professional formation emphasizes the technical dimension, leaving out the professional's internal growth. Searching for understanding that process, our goal is to identify and to analyze the perception and feelings of nursing teaching staff, related to their formation as a person and as a professional in the of Nursing scope. The reports that were submitted to the content analysis pointed out two categories: Holism only in theory and Scheme of the feelings, revealing a stage of many discoveries and little space for the student person. The results of the research offered important elements to think about it by the Schools, visualizing the student's formation as an integral and integrated person.
\end{abstract}

\section{KEYWORDS}

Holistic nursing.

Education, nursing.

Mental health

\section{RESUMEN}

A pesar del discurso de la integridad del ser humano, nosotros observamos que la formación de los enfermeros da énfasis a la dimensión técnica y deja de instrumentalizar el crecimiento interior del profesional. Tratando de entender este proceso, objetivamos identificar y analizar la percepción y los sentimientos de los estudiantes del Pre grado de enfermería, relacionando su formación como persona/profesional en el ámbito de la Enfermería. Los relatos sometidos a análisis de contenido, identificaron dos categorías: Holismo sólo en la teoría $y$ Trama de los sentimientos, revelaron que esta es una fase de muchos descubrimientos y poco espacio para la formación de la persona del estudiante. Los resultados de esta investigación ofrecen elementos importantes a ser pensados por las Escuelas buscando la formación del estudiante como persona integral/integrada.

\section{PALABRAS CLAVE}

Enfermería holística. Educación en enfermeria. Salud mental. 


\section{INTRODUÇÃO}

Enquanto docentes do Ensino Superior na área da saúde, temos observado que o processo de formação acadêmica não tem privilegiado aspectos que possibilitem o fortalecimento emocional dos futuros profissionais de saúde, num nítido movimento de desconsideração dos agravos produzidos pelas situações ansiogênicas as quais os alunos estão continuamente expostos.

A postura dos educadores e profissionais com quem os alunos interagem ao longo dos cursos da área da saúde, pouco os estimulam a considerarem o que pensam e, principalmente, o que sentem quando se vêem confrontados com a vulnerabilidade humana. Esse é o reflexo de anos de cristalização desse modelo, o que sinaliza que o ensino das profisssões de saúde deverá passar por profundas mudanças nas próximas décadas, pois se evidenciam sinais de esgotamento exigindo a construção de novos modelos de formação e capacitação de recursos humanos em saúde ${ }^{(1)}$.

A Enfermagem tem buscado seu espaço, enquanto profissão, voltando-se para o cuidado das pessoas que assiste, constituindose esta a razão maior do seu trabalho. No entanto, a despeito de lidar com o ser humano, a forma como seu trabalho tem sido concebido contribui para que suas atividades sejam dispostas de maneira fragmentada, despersonalizando a pessoa que cuida e, invariavelmente a sua própria.

Se o enfermeiro não for respeitado e considerado integralmente como ser humano, pode apresentar dificuldades para se ver e se relacionar de forma diferente com o outro. Assim, não se pode exigir dele que seja afetivo, por exemplo, quando isso ele não tem ou não aprendeu a valorizar, pois só oferecermos ao outro aquilo que possuímos ${ }^{(2-3)}$.

Com base nessas considerações, questionamos como poderemos cuidar do outro, olhar para ele, vê-lo como pessoa que se apresenta com sentimentos e emoções, se não conseguimos fazer o mesmo conosco?

Apesar de dirigirmos nossa atenção para os profissionais de saúde, salientamos nesta pesquisa, o enfermeiro, especificamente o aluno de Enfermagem, partindo do entendimento que ele deve ser atendido enquanto pessoa, ainda no período da sua formação acadêmica.

Temos defendido tais idéias, acreditando ser necessário repensarmos nossas atitudes frente ao indivíduo que atendemos, focando nossa relação com ele não mais no modelo biomédico, mas na dimensão bio-psicosocial que valoriza o cuidado à pessoa ${ }^{(4-11)}$.

Não raramente, somos procurados por alunos referindo que problemas de ordem pessoal estão atrapalhando seu rendimento nas atividades acadêmicas. Outros, ao contrário, fazem contato com suas próprias limitações diante de circunstâncias estressantes relativas à profissão, como a dor e o sofrimento daqueles de quem cuidam.

Temos verificado que a idade dos alunos, ao entrarem para Universidade, é cada vez menor, estando muitos deles em plena adolescência e, portanto, passando por um período de desenvolvimento importante e peculiar em suas vidas. Chegam geralmente ao meio acadêmico sob forte estresse e pressão, por força do vestibular, apresentando uma série de expectativas e desejos, condizentes com o momento que estão vivenciando como universitários.

Ao adentrarem no curso deparam-se, muitas vezes, com uma realidade nem sempre em consonância com a esperada, tanto em relação ao curso como às condições de ensino, percebendo-se diante de uma nova etapa de suas vidas, onde são chamados à responsabilidade pelo próprio caminhar e pelas escolhas a serem feitas.

Essas experiências influenciam os pensamentos, sentimentos e ações dos alunos e, a despeito disso, nem sempre são levados em consideração, pelas instituições formadoras. Embora muitos estudos chamem a atenção para a humanização da assistência, idéia que compartilhamos e valorizamos, entendemos que esta proposta será mais significativa, se pensarmos a humanização do ensino a partir dos relacionamentos estabelecidos durante o processo de formação. Isso sem dúvida, exigirá uma nova postura por parte dos educadores que deverão centrar o ensino na pessoa, ou seja, no aluno ${ }^{(12-14)}$.

Debruçar sobre esses elementos, com vistas ao ensino centrado na pessoa, abarcando não somente a competência técnica $\mathrm{e}$ racional do aluno, mas sua totalidade, con-
Holismo só na teoria: a trama de sentimentos do acadêmico de enfermagem sobre sua formação 
Elizabeth Esperidião Denize Bouttelet Munari cebendo-o como alguém que possui atributos pessoais e que experimenta diversos sentimentos quando implementa suas ações profissionais, torna-se um investimento fundamental, quando se busca o ser integral e integrado naquilo que faz.

Diante disso, fazemos alguns questionamentos: como o aluno de Enfermagem está percebendo a sua formação? Será ele compreendido pelo professor na sua totalidade, ou seja, enquanto ser humano que está a serviço de uma profissão e, que para tanto deve ser preparado nas dimensões humanitária, pessoal, ampla e completa?

Por considerarmos urgente uma revisão do modelo atual do ensino, frente às necessidades de capacitar o profissional para compreender o cuidado humano além da abordagem do doente e da doença, foi que estabelecemos para esse estudo os seguintes objetivos: identificar e analisar as percepções do aluno do curso de graduação em Enfermagem, com relação à sua formação como pessoa/profissional no âmbito da Enfermagem e identificar e analisar os sentimentos expressos pelos alunos sobre sua formação, ao longo da sua trajetória acadêmica no curso de Enfermagem.

\section{PERCURSO METODOLÓGICO}

Pela natureza da presente investigação, consideramos a abordagem qualitativa a mais adequada para responder aos objetivos propostos, uma vez que esta procura centrar a atenção na especificidade, no individual, almejando sempre a compreensão dos fenômenos estudados. Preocupa-se em conhecer as estruturas em que a experiência se verifica, sendo entendida como um método de compreensão e de reflexão sobre um tema ${ }^{(15-16)}$.

O projeto recebeu parecer favorável do Comitê de Ética em Pesquisa da Escola de Enfermagem de Ribeirão Preto da Universidade de São Paulo, sob protocolo n ${ }^{\circ}$ 0085/2000.

Assim, este estudo foi desenvolvido numa universidade pública, com alunos da segunda à quinta série do curso de graduação em Enfermagem. Não incluímos os alunos da primeira série, uma vez que a coleta de dados ocorreu no início do ano letivo e consideramos que os ingressantes ainda não tinham elementos para responder aos questionamentos, o que poderia interferir no alcance dos objetivos desta investigação.
O critério para seleção dos sujeitos foi a sua disponibilidade voluntária em participar do mesmo. Dessa maneira, em cada série, apresentamos e expusemos o tema em questão, solicitando que os alunos, espontaneamente, manifestassem sua vontade em participar da pesquisa. Obtivemos um total de 21 sujeitos, em média 4 alunos por série que, por ocasião da coleta de dados, registraram seu consentimento em formulário próprio, seguindo as normas de pesquisa com seres humanos do Conselho Nacional de Saúde (CNS), atendendo a Resolução 196/96.

A técnica utilizada para a coleta de dados foi a entrevista semi-estruturada, por considerarmos que ela permite ao pesquisador orientar seus questionamentos, sem a necessidade de uma seqüência rígida nas questões feitas, pois a direção é tomada a partir do conteúdo que emerge da fala do entrevistado, ao discutir o assunto em foco.

Assim, em pertinência aos objetivos e no sentido de facilitar as entrevistas, elaboramos um instrumento de coleta de dados, contendo as seguintes questões orientadoras: Qual sua percepção sobre a sua formação (pessoal / profissional) durante o curso de Enfermagem? Como o curso contempla sua formação no aspecto pessoal e também profissional? Privilegia algum? Quais os sentimentos que você experimentou durante o curso, até agora? Você considera que os professores o vêem, como uma pessoa, durante o curso? Há uma preocupação do curso voltada para o seu autoconhecimento? Há algum reconhecimento do curso, em relação a você, no que diz respeito ao seu lado pessoal?

Para o desenvolvimento desta técnica cuidamos para que, após o consentimento da pessoa, a entrevista fosse conduzida em ambiente reservado, gravada em fita cassete e, posteriormente transcrita na íntegra, mantendo-se o anonimato dos participantes ${ }^{(15-16)}$.

Os dados coletados, por sua própria natureza e subjetividade, foram analisados qualitativamente, sendo sistematizados conforme o esquema da técnica de análise de conteúdos, mais especificamente através da análise temática ${ }^{(17)}$.

Esta técnica consiste em descobrir os núcleos de sentido que compõem a comunicação e cuja presença, freqüência de aparição podem significar alguma coisa com o objetivo analítico escolhido( ${ }^{(17)}$. 
Seguimos rigorosamente as etapas previstas pela técnica como a pré-análise, a exploração do material e o tratamento dos resultados, incluindo a inferência e a interpretação, entendendo ser este o caminho necessário para uma aproximação fiel ao nosso objeto de estudo, diante do conteúdo expresso pelos entrevistados.

\section{RESULTADOS E DISCUSSÃO}

Estabelecemos um diálogo com os dados encontrados em todo o processo de análise, tomando por base as contribuições que a literatura oferece, promovendo uma discussão interativa entre o conteúdo das entrevistas e as elaborações oriundas da nossa experiência.

No geral, não notamos diferenças significativas nos resultados entre as séries, razão pela qual optamos por apresentá-los e discuti-los em um contexto mais geral, fazendo as devidas marcações, quando necessário. Assim, identificamos duas categorias, que fazem relação entre si e que se apresentaremos a seguir: Holismo só na teoria e a Trama dos sentimentos.

\section{Holismo na Teoria}

Nesta categoria, discutimos a concepção que o aluno tem do seu processo de formação acadêmica, ou seja, aquela que considera o conhecimento técnico-científico na formação profissional. Para melhor compreender o conteúdo expresso nessa categoria, apresentaremos os aspectos de análise evidenciados.

\section{Tendências da formação}

As entrevistas em todas as séries apontaram que a formação do aluno está mais voltada para questões profissionais, privilegiando o desenvolvimento de conhecimentos teóricos e práticos relativos ao desempenho de atividades próprias da profissão:

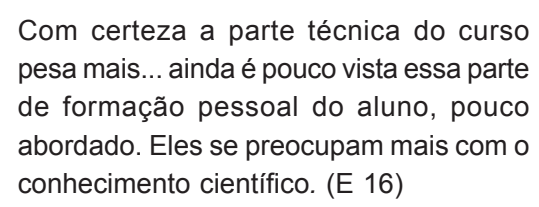

A formação tem priorizado conteúdos teóricos e ensinamentos práticos embasados nas inúmeras técnicas de enfermagem e o conhecimento científico, que têm sido apresentados aos alunos, muitas vezes, através de aulas exaustivas, sem a devida relevância do seu significado real e desarticuladas entre si, não oferecendo o retorno desejado para os que estão diretamente envolvidos nesse processo, seja aluno, professor, ou a própria assistência de enfermagem.

Existem estudos que apontam para o privilégio do tecnicismo no preparo do profissional, se compararmos ao que é investido no desenvolvimento da pessoa, a despeito da necessidade de instrumentalizá-la para atuar de forma mais plena ${ }^{(18-20)}$.

Assim, é preocupante a distorção de valores no processo de ensino-aprendizagem, uma vez que para ser significativo, o aprendizado deve ser norteado por premissas que atendam às questões de caráter mais pessoal, como

independência, auto-iniciativa e responsa-
bilidade, libertação de criatividade, tendên-
cia para se tornar, mais, uma pessoa ${ }^{(12)}$.

Quanto à qualidade da formação ofereci$\mathrm{da}$, verificamos que o curso satisfaz às necessidades e expectativas dos alunos, conforme os depoimentos a seguir:

\begin{abstract}
A formação profissional, com este novo currículo, a gente tem uma abrangência boa; eu acho que é mais profissional que pessoal. (E 7)
\end{abstract}

$\mathrm{O}$ fato dos entrevistados apontarem a primazia da formação profissional que a instituição oferece, em função do seu corpo docente, nos aquieta, na medida em que reconhecemos a capacidade dos professores que $\mathrm{o}$ integra, indicando que o esforço empenhado por ocasião da reforma curricular está surtindo efeito, aumentando a possibilidade de solidificar a discussão que ora estamos propondo.

Com referência ao atendimento das expectativas dos alunos, identificamos que estas podem estar sendo atendidas em função do modelo de formação tradicional, mais comum e familiar no contexto educacional, onde a satisfação das necessidades atinentes ao curso relaciona-se diretamente com o aprendizado dos procedimentos técnicos.

\section{Formação fragmentada}

Encontramos poucos elementos nas falas dos entrevistados que caracterizassem o processo de formação integral, ou seja, de
Holismo só na teoria: a trama de sentimentos do acadêmico de enfermagem sobre sua formação 
Elizabeth Esperidião Denize Bouttelet Munari forma a contemplar equilibradamente suas necessidades pessoais e profissionais

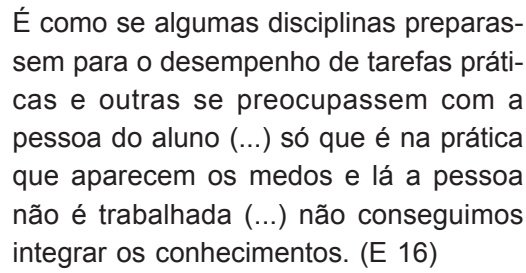

É como se algumas disciplinas preparassem para o desempenho de tarefas práticas e outras se preocupassem com a pessoa do aluno (...) só que é na prática que aparecem os medos e lá a pessoa não é trabalhada (...) não conseguimos integrar os conhecimentos. (E 16)

No ensino tradicional, o aspecto integrativo do conhecimento é menosprezado, sendo oferecido ao aluno de forma fracionada, causando dificuldades para ele constituir um todo significativo. A gestaltpedagogia propõe o aprendizado em unidades integradas em conteúdo correspondentes aos contextos reais de vida ${ }^{(21)}$. Os alunos afirmam que os professores, falam muito no holismo, porém esta abordagem não é vivenciada por eles ao longo da sua formação. A esse respeito uma autora admite que, embora essas opiniões sejam amplamente adotadas de forma intelectual e até, por vezes, sentidas em nível emocional, talvez não se manifestem em $\operatorname{atos}^{(22)}$.

\section{Em questão a sentimentos acho que não há preparo. Acho que há muita preocupa- ção na questão do paciente... você traba- Iha o físico do paciente, o psicológico do paciente, mas o psicológico do estudan- te, ele não é trabalhado... é cobrado da gente que nós cuidemos desses pacien- tes de uma maneira holística, você vê-lo como um todo. Só que aqui dentro, a ques- tão do aluno, a maioria dos professores não vêem a gente como um todo. (E 1)}

Embora o curso de Enfermagem ao qual estamos nos referindo tenha delineado a concepção holística nos seus princípios, os resultados mostram que a tendência da formação é centrada nos procedimentos técnicos e nas necessidades do paciente, sem contemplar a pessoa do aluno.

\section{Em busca da integração}

O fenômeno da cisão que permeia a trajetória acadêmica, conforme pudemos identificar nas entrevistas, suscita no aluno algumas preocupações, desejos e sentimentos, muitos deles coincidentes com os nossos. Encontramos depoimentos que demonstram seu interesse em ter mais oportunidades para trabalhar de modo integrado:
Acho que está faltando um pouco de integração, de deixar mais claro para o aluno desde o $1^{\circ}$ ano essa formação pessoal dele, para refletir enquanto profissional. (E 17)

Constatamos, ao mesmo tempo, que alguns entrevistados referem excelência na capacidade dos docentes embora, isso não atende às suas necessidades relacionais:

Os professores são excelentes, ajudam muito, mas este lado de interagir com os sentimentos, com a prática (...) faltou. (E 21)

O professor ensina bem, mas toda vez que eu vou para o campo, fico ansiosa (...) vários blocos de estágio e cada um é um terror pra mim (...) às vezes eu chego a passar mal (...) o curso não trabalha isso. (E 16)

Chama nossa atenção falas de alunos que referem que o professor é bom, "o professor ensina bem, mas senti medo", pois elas parecem manter um sentido do incompleto, não satisfazendo o aluno, ao mesmo tempo em que sugerem boa qualificação do docente.

Por outro lado, a maioria dos entrevistados percebe que a preocupação do aluno enquanto pessoa fica sob a responsabilidade quase que exclusiva da área de saúde mental.

A Saúde Mental conseguiu fazer que a gente visse essa coisa como um todo, não só do paciente, mas da gente (...) (E 17)

\section{O papel do professor}

As entrevistas mostraram, que a possibilidade de uma relação mais significativa é restrita a algumas experiências marcadas mais pela afetividade e afinidades pessoais, com determinados professores, do que, necessariamente, pela proposta do curso.

Quando é um professor que você já conhece e acha que é mais acessível a gente até chega, conversa, pede orientação, expõe o problema .... (E 7)

Precisamos reconhecer que a postura empática por parte do professor é fundamental para ajudar a pessoa do aluno e, mesmo estando numa situação diferente da dele, devemos procurar sentir a especificidade do seu mundo interior. Dessa maneira, exerceremos a função de catalisadores dos seus significados, sobretudo emocionais, facilitando o processo através da compreensão empática ${ }^{(23-24)}$. 
Parece que muitos de nós desconhecemos o poder das nossas atitudes no exercício da docência relacionadas à herança que deixamos aos futuros profissionais.

(...) era o que o mais experiente falava, pra tentar ser mais forte, sofrer menos ( ...) daqui a alguns anos eu vou reagir deste jeito (...) eu dou mais atenção a lição de vida que a professora dá porque aprendo mais que com a matéria. (E 19)

A formação do educador passa a ser peça chave, pois não é possível esperar do docente uma postura humanizada, na medida em que foi preparado para exercer sua profissão apenas do ponto de vista técnico, de repassador de conhecimento.

\section{Contribuições do curso}

Apesar do Curso de Enfermagem em questão não ter objetivos específicos quanto ao desenvolvimento da pessoa, constatamos que algumas experiências adquiridas no decorrer dele têm contribuído tanto para o crescimento como para o amadurecimento dos alunos, na medida em que acrescentam algo na sua bagagem pessoal.

\begin{abstract}
Eu me tornei mais responsável, mais observadora (...) e a enfermagem tem me dado isso, de estar melhorando o meu comportamento, de estar aprendendo a controlar meus sentimentos (...) melhorei a convivência, aprendi a ouvir, a prestar mais atenção nas pessoas. (E 13)
\end{abstract}

Alguns entrevistados referem-se a vivência da prática profissional como influência direta para suas questões como indivíduo, assim como seus problemas pessoais influenciam o desempenho profissional:

O lado pessoa vai também para a prática, depende do que acontece lá, eu fico ou triste ou feliz. (E 2)

Os depoimentos citados a seguir nos levam a considerar que para os profissionais atuarem de forma inteligente no processo da doença é preciso que aceitem, compreendam e manifestem, de modo mais amplo a totalidade de sua própria natureza humana ${ }^{(22)}$.

A gente tem a preocupação de estar sabendo que a gente pode ser um instrumento para auxiliar e cuidar (...) a gente sabe que para cuidar de alguém, a gente tem que estar bem com a gente. (E 7)
Acreditamos na necessidade do auto conhecimento como facilitador do nosso posicionamento enquanto pessoa. Outras autoras comungam da mesma percepção afirmando isso ser possível quando conseguirmos conciliar e estender os pressupostos da assistência integral e humanizada àqueles que cuidam, ou seja, nós mesmos ${ }^{(25-27)}$.

\section{A Trama dos Sentimentos}

Esta categoria apresenta os sentimentos vivenciados pelos estudantes durante o curso, os quais manifestaram de forma diversificada, modificando-se e alternando-se desde a euforia pela passagem no vestibular, realização, alegria, curiosidade, interesse em crescer, orgulho por fazer Enfermagem, até sentimentos de angústia, tristeza, medo, terror, fracasso, solidão, sensação de desamparo, inferioridade, incapacidade, decepção, vontade de desistir, raiva, revolta, insegurança, pena, sofrimento e dor. Percebemos, de um modo geral, a dificuldade em falar de suas emoções ou em apreender o sentido das perguntas durante a entrevista que se relacionavam com esse aspecto.

Embora reconheçamos que muitos deles se completem, tal como as polaridades alegria e tristeza, entusiasmo e decepção, sua classificação baseou-se no entrelaçamento entre os sentimentos citados e as situações que os evocavam, o que gerou três aspectos de análise que apresentamos a seguir.

\section{Sentimentos decorrentes das experiências do processo ensino-aprendizagem}

A maioria dos sentimentos relatados pelos alunos surge em decorrência do que vivenciam na prática, conforme apontam as seguintes falas:

Sinto pena dos pacientes, dó pelo sofrimento deles (...) um sentimento depressivo porque tive que fazer um curativo com uma escara e fiquei depressiva pela minha fraqueza (...) (E 4)

Temos a convicção de que o profissional de saúde, ao trabalhar com pessoas e lidando com suas emoções e sentimentos, não consegue colocar a sua própria pessoa à margem desse processo, de modo que, o contato estabelecido pelo profissional no momento do cuidado, pode suscitar a mobilização de seus próprios sentimentos ${ }^{(28)}$.
Holismo só na teoria: a trama de sentimentos do acadêmico de enfermagem sobre sua formação 
Em muitas entrevistas, os alunos deixaram clara a dificuldade que encontraram para lidar com seus sentimentos.

Às vezes a gente fica meio perdido e você sente que você está só, que não pode contar, então você não sente que alguém pode te ajudar. (E 8)

Parece que nesse relato, o aluno se ressente da falta da ajuda do professor, quando ele mais precisa, o que nos sugere ocorrer em alguns momentos. Em contrapartida, na posição de docentes, muitas vezes nos deparamos com situações onde percebíamos dificuldades do aluno e nem por isso notávamos seu movimento na busca de auxílio ou mesmo em aceitar ajuda, quando the era oferecida de alguma forma.

\section{Sentimentos decorrentes da relação professor-aluno}

Outro aspecto evidenciado através dos relatos e que merece destaque na análise é a intrínseca relação entre os sentimentos manifestos pelos alunos e a atitude assumida pelo professor.

\section{Eu estava dando tudo de mim no estágio e a professora achando que ainda era pouco... nesse momento eu não me senti pessoa... eu me senti um objeto de estu- do, sabe? Me senti desconsiderado. (E 1)}

Apesar de nos últimos anos ter crescido a compreensão de que a saúde é influenciada tanto pela realidade subjetiva quanto pela objetiva, esses aspectos estão mais voltados para o paciente. Ainda se discute a legitimidade desta experiência para o profissional, a emoção parece ser a maior ameaça à sua imagem, bem como a dimensão humana mais difícil de ser reincorporada aos relacionamentos contemporâneos nos cuidados da saúde ${ }^{(22)}$.

A maioria das entrevistas referenda que as emoções do aluno não são trabalhadas durante o curso, nem recebem algum tipo de tratamento por parte dos docentes. A ajuda geralmente varia em função das possibilidades do professor ou pela proximidade que o aluno tem com ele, para trabalhar tais questões:

Acho que os professores não estão preparados para isto (...) então não tem nem como exigir deles. (E 6)
Os depoimentos colocam ênfase nas relações interpessoais estabelecidas, em especial, com os docentes e no possível crescimento pessoal decorrentes delas. Os alunos aprendem muitas vezes, embora de maneira implícita, que emoções prejudicam o raciocínio, julgamento e habilidades para agir de maneira decisiva, o que os leva a reprimir sentimentos, por acreditar que deste modo poderão atender melhor às pessoas.

Algumas falas mostram que os alunos tendem a lidar com suas sensações elaborando-as racionalmente, sendo, por vezes, assim incentivados pelo professor, que ao assumir tal atitude, coloca a responsabilidade no aluno pela busca e satisfação das suas necessidades pessoais, permanecendo fora do processo:

Eu tremia e suava mais do que (...) mas você aprende aqui na escola: você dá conta, mas se não der jeito de trabalhar a cabeça (...) tem que se preparar melhor (...) tem que se controlar porque senão você não consegue fazer nada. (E 21)

Encontramos também entrevistados referindo sentirem-se "alunos", numa nítida separação entre aquele que faz (aluno) e o outro que sente (pessoa).

Em algumas circunstâncias a gente até sente meio aluno, aluno, assim, entre aspas. As professoras pensam que a gente é maquininha e tem tudo sempre à hora, que não tem sentimento.Um dia eu precisei separar tudo o que estava sentindo para ser aluno. (E 8)

Nesse particular, percebemos que os alunos não têm ainda a compreensão acerca do significado do seu fazer, pois utilizam as expressões maquininha e robozinho que indicam o sentido de armazenamento e reprodução, presentes no princípio do funil da teoria $\operatorname{rogeriana}^{(12)}$.

\section{Dificuldade de contato}

Notamos, durante as entrevistas, que grande parte dos alunos demonstrou dificuldade em abordar suas percepções e sentimentos.

Toda vez que falo do que sinto, olha como fica minha mão super gelada. Eu sinceramente não sei que sentimento (...) é difícil falar um pouquinho de mim, do que eu sinto, porque não tenho esse costume, fico ansiosa, não sei dizer sentimento específico, fico nervosa. (E 16) 
As pessoas possuem, geralmente, a tendência em considerar seus sentimentos como algo subjetivo ou indigno de confiança, entretanto, precisamos ajudá-las a confiar neles como indicadores de algo importante que se passa com elas. O caminho da compreensão vem de dentro, facilitando a expressão de emoções, permitiremos a clarificação da realidade interna ${ }^{(24)}$.

Houve uma entrevistada que deixou evidente que seus temores vivenciados no campo de estágio, diante da morte, eram conhecidos dela e a acompanhavam desde sua adolescência. Trabalhar essa questão pode desencadear um processo de crescimento para o aluno, pois partindo das suas próprias necessidades, possivelmente haverá uma modificação na sua relação com o meio.

\section{CONSIDERAÇÕES FINAIS}

O interesse pelo tema trazido nesse trabalho permeia toda nossa trajetória de vida e o fato de convivermos no meio acadêmico possibilitou a observação de que o princípio da integralidade do ser humano, apesar de ser fortemente enunciado, é pouco aplicado na formação do enfermeiro em se tratando do cuidado com ele próprio.

Neste estudo não nos propusemos ao aprofundamento dessa discussão, mas apontamos a necessidade da tomada de consciência acerca dos resultados encontrados, com vistas à integração das idéias que são defendidas pela academia e as ações colocadas em prática.

Destacamos o valor dos docentes na facilitação desse processo, que deve ser bem conduzido tanto para o desempenho profissional, como pessoal, facilitando o posicionamento do aluno diante da vida.

Muitas vezes, no exercício da docência, esquecemos de humanizar nossas relações com os alunos, que são uma réplica de nossos "pacientes mais próximos", privando a eles e também a nós mesmos a oportunidade de experienciarmos o discurso que teoricamente defendemos.

Os resultados deixam claro que os alunos comungam esse pensamento, na medida em que relatam uma desarticulação entre o que aprendem para a vida profissional e o que se apropriam para a sua dimensão pessoal. Embora tal situação lhe traga sentimentos muitas vezes desconfortáveis, é também responsável pelo seu crescimento pessoal, na medida em que a trajetória acadêmica lhe possibilita o desenvolvimento, sem necessariamente, a participação direta dos professores ou da proposta do curso.

Nossa impressão de que a formação acadêmica vem acontecendo de maneira fragmentada, encontrou eco entre os alunos que, além de perceberem um distanciamento entre o que é ensinado e o que vivenciam, podem incorporar esse pensamento dicotomizado no exercício profissional.

Outro aspecto que consideramos relevante é a contribuição das disciplinas da área da saúde mental, como oportunidade ímpar, no favorecimento do contato do aluno com os seus aspectos pessoais, de expressão de sentimentos, além de possibilitar o encontro com ele mesmo, enquanto sertotal. Verificamos que a responsabilidade em se abordar e discutir questões relativas ao relacionamento seja intra ou interpessoal, continua sendo tarefa quase que exclusiva desta especialidade.

Defendemos, portanto, o investimento no desenvolvimento da abordagem holística no processo de formação do enfermeiro, considerando a humanização do ensino uma estratégia necessária para o estabelecimento de relações humanizadas com as pessoas que este profissional assiste.
Holismo só na teoria: a trama de sentimentos do acadêmico de enfermagem sobre sua formação

\section{REFERÊNCIAS}

(1) Machado JLM, Caldas A, Bertoncello NMF. Uma nova iniciativa na formação dos profissionais de saúde. Interface-Comunic, Saúde, Educ 1997; 1(1):147-56.

(2) Travelbee J. Intervencion en enfermeria psiquiatrica. Colômbia: Carvajal; 1979.
(3) Buscaglia L. Vivendo, amando e aprendendo. $18^{\mathrm{a}}$ ed. Rio de Janeiro: Record; 1995.

(4) Esperidião E. Utilizando sucata na relação terapêutica. Rev Bras Enferm 1999; 52(3): 469-78.

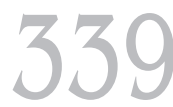

Rev Esc Enferm USP 2004; 38(3):332-40. 
Elizabeth Esperidião Denize Bouttelet Munari
(5) Esperidião E. Desenvolvendo a pessoa, desenvolvendo o profissional. Rev VI Encontro Goiano da Abordagem Gestáltica 2000; (6):121-30

(6) Esperidião E, Capel J. Contatando o ser psicólogo através da sucata. Rev V Encontro Goiano da Abordagem Gestáltica, 1999; (5):107-10.

(7) Esperidião E, Munari DB, Stacciarini JMR. Desenvolvendo pessoas: a importância do autoconhecimento para a formação do enfermeiro. Rev Lat Am Enferm 2002; 10(4): 516-22.

(8) Esperidião E, Munari DB. Repensando a formação do enfermeiro e investindo na pessoa: algumas contribuições da abordagem gestáltica. Rev Bras Enferm 2000; 53(3): 415-23.

(9) Esperidião E. A arte do encontro: trabalhando o ser pessoa e o ser profissional [Apresentado ao $4^{\circ}$ Congresso Brasileiro de Arteterapia; 2000 set 10 ; Goiânia].

(10) Esperidião E. Desenvolvendo pessoas: uma abordagem holística na formação profissional. In: Programa e anais do $7^{\circ}$ Congresso Internacional de Gestalt; 2000 out. 26-29; Rio de Janeiro. Rio de Janeiro; 2000. p.32.

(11) Esperidião E. Vivenciando o encontro: ser pessoa $\mathrm{X}$ ser profissional. In: Programa e anais do $7^{\circ}$ Congresso Internacional de Gestalt; 2000 out.26-29; Rio de Janeiro. Rio de Janeiro; 2000. p. 41.

(12) Rogers CR. Liberdade para aprender. Belo Horizonte: Interlivros; 1978.

(13) Rogers CR.Tornar-se pessoa. $4^{\mathrm{a}}$ ed. São Paulo: Martins Fontes; 1991.

(14) Rogers CR. Terapia centrada no cliente. São Paulo: Martins Fontes; 1992

(15) Triviños ANS. Introdução à pesquisa em ciências sociais: a pesquisa qualitativa em educação. São Paulo: Atlas; 1992.

(16) Minayo MCS. O desafio do conhecimento: pesquisa qualitativa em saúde. $3^{\mathrm{a}}$ ed. São Paulo. Hucitec; 1994.
(17) Bardin L. Análise de conteúdo. Lisboa: Edições 70; 1977.

(18) Brant MJCGC, Antunes MJM. Concepções pedagógicas: influência na educação e na prática de enfermagem. In: Sínteses do $47^{\circ}$ Congresso Brasileiro de Enfermagem; 1995 nov.19-24; Goiânia. Goiânia: UFG; 1995. p.169-70.

(19) Munari DB, Rodrigues ARF. Enfermagem e grupos. Goiânia: AB; 1997.

(20) Stacciarini JMR, Esperidião E. Repensando estratégias de ensino no processo de aprendizagem. Rev Lat Am Enferm 1999; 7(5): 59-66.

(21) Burow O. Scherpp K. Gestaltpedagogia: um caminho para a escola e a educação. $3^{\mathrm{a}}$ ed. São Paulo: Summus; 1985.

(22) Remen RN. O paciente como ser humano. São Paulo: Summus; 1993.

(23) Benjamin A. A entrevista de ajuda. São Paulo: Martins Fontes; 1998.

(24) Rudio FV. Orientação não diretiva na educação, no aconselhamento e na psicoterapia. $13^{\mathrm{a}}$ ed. Petrópolis: Vozes; 1999.

(25) Leoni MG. Autoconhecimento do enfermeiro da relação terapêutica. Rio de Janeiro: Cultura Médica; 1996.

(26) Rodrigues ARF, Scatena MCM, Giacon AV, Santana JA. Opinião de enfermeiros a respeito de suas interações com os pacientes. In: Anais do $1^{\circ}$ Congresso de Saúde Mental do Estado do Rio de Janeiro; 1997. Rio de Janeiro: Tecorá; 1997. p. 455-71.

(27) Silveira RS, Lunardi VL. O conhecimento de si como possibilidade para a transformação de si e do coletivo. Rev Bras Enferm 1999; 52(4):514-9.

(28) Gonzalez RMB, Beck CLC, Denardin ML. Cenários de cuidados: aplicação de teorias de enfermagem. Santa Maria: Pallotti; 1999. A autopercepção: um trajeto vivenciado por enfermeiras; p. 13-32. 